\title{
Effect of a mitochondria-targeted vitamin E derivative on mitochondrial alteration and systemic oxidative stress in mice
}

\author{
Gaowei Mao ${ }^{1,2} \dagger$, George A. Kraus ${ }^{3},{\text { Ikyon } \mathrm{Kim}^{3} \ddagger \text {, Michael E. Spurlock }}^{1,2,4}$, Theodore B. Bailey ${ }^{5}$ \\ and Donald C. Beitz $z^{1,2,6 *}$ \\ ${ }^{1}$ Interdepartmental Graduate Program in Nutritional Sciences, Iowa State University, Ames, IA 50011-3150, USA \\ ${ }^{2}$ Department of Animal Science, 313 Kildee Hall, Iowa State University, Ames, IA 50011-3150, USA \\ ${ }^{3}$ Department of Chemistry, Iowa State University, Ames, IA 50011-3150, USA \\ ${ }^{4}$ Department of Food Science and Human Nutrition, Iowa State University, Ames, IA 50011-3150, USA \\ ${ }^{5}$ Department of Statistics, Iowa State University, Ames, IA 50011-3150, USA \\ ${ }^{6}$ Department of Biochemistry, Biophysics and Molecular Biology, Iowa State University, Ames, IA, 50011, USA
}

(Received 12 July 2010 - Revised 1 December 2010 - Accepted 14 December 2010 - First published online 16 February 2011)

\section{Abstract}

The objective of the present study was to determine whether a mitochondria-targeted vitamin E derivative (MitoVit E) would affect certain mitochondrial parameters, as well as systemic oxidative stress. A total of sixty-four mice were fed a high-fat (HF) diet for 5 weeks. They were then switched to either a low-fat (LF) or a medium-fat (MF) diet, and administered orally with MitoVit E ( $40 \mathrm{mg}$ MitoVit E/kg body weight) or drug vehicle $\left(10 \%(\mathrm{v} / \mathrm{v})\right.$ ethanol in $0.9 \%(\mathrm{w} / \mathrm{v}) \mathrm{NaCl}$ solution), every other day for 5 weeks. Mitochondrial ATP and $\mathrm{H}_{2} \mathrm{O}_{2}$ production rates in both the liver and the gastrocnemius were not affected by MitoVit E administration in either LF or MF diet-fed mice. However, the number and average size of the subsarcolemmal mitochondria, but not the intermyofibrillar mitochondria, from the soleus muscle were significantly higher in the MF group receiving MitoVit E (MF-E) than in the MF group receiving vehicle only (MF-C). After the mice were switched from the HF diet to the four dietary treatments (LF-C, LF-E, MF-C and MF-E), the decrease in urinary isoprostane concentration was significantly greater in the LF-E group than in the other three groups during the whole study (weeks 6-10). In addition, MitoVit E significantly increased plasma superoxide dismutase (SOD) activity in the MF diet-fed group without affecting plasma glutathione peroxidase activity or $\mathrm{H}_{2} \mathrm{O}_{2}$ levels. Overall, these data suggest that MitoVit E affects subsarcolemmal mitochondrial density and systemic oxidative stress parameters such as plasma SOD activity and urinary isoprostane concentration.

\section{Key words: Mitochondria-targeted vitamin E derivatives: Mitochondria: Oxidative stress}

Mitochondria are often referred to as the powerhouse of the cell because they consume nearly $90 \%$ of cells' oxygen to support oxidative phosphorylation for the synthesis of ATP, the energy currency used for a variety of metabolic reactions. Mitochondrial ATP production occurs when electrons are passed along a series of molecular complexes in the inner mitochondrial membrane known as the electron transport chain. The energy released by the flow of electrons through the electron transport chain is used to transfer protons across the inner mitochondrial membrane, creating a large mitochondrial membrane potential, which is used to drive ATP synthesis as protons re-enter the mitochondrial matrix through the $\mathrm{F}_{0} \mathrm{~F}_{1}$ ATP synthase ${ }^{(1)}$. Ideally, the transfer of electrons across the electron transport chain should result in the four-electron reduction of molecular oxygen $\left(\mathrm{O}_{2}\right)$ to water $\left(\mathrm{H}_{2} \mathrm{O}\right)$. However, this is not always the case.

During the transfer of electrons along the electron transport chain, single electrons sometimes escape and result in a single electron reduction of molecular oxygen to form a superoxide anion $\left(\mathrm{O}_{2}^{\bullet^{-}}\right)^{(2)}$. It is estimated that as much as $1 \%$ of all oxygen consumed may result in the formation of reactive oxygen species (ROS) such as $\mathrm{O}_{2}^{\bullet-}$, with the vast majority of ROS being generated in the mitochondria ${ }^{(3)}$, supporting the prevailing opinion that the mitochondria are the major site

\footnotetext{
Abbreviations: GPx, glutathione peroxidase; HF, high fat; LF, low fat; LF-C, LF group receiving drug vehicle; LF-E, LF group receiving mitochondria-targeted vitamin E derivative; MF, medium-fat; MF-C, MF group receiving drug vehicle; MF-E, MF group receiving mitochondria-targeted vitamin E derivative; MitoVit E, mitochondria-targeted vitamin E derivative; ROS, reactive oxygen species; SOD, superoxide dismutase.
}

*Corresponding author: Distinguished Professor D. C. Beitz, fax +1 515 294-3795, email dcbeitz@iastate.edu

†Present address: B180 Medical Laboratories, Free Radical and Radiation Biology Program, University of Iowa, Iowa City, IA 52 242-1181, USA.

$\ddagger$ Present address: Center for Medicinal Chemistry, Korea Research Institute of Chemical Technology, Daejeon 305-600, Republic of Korea. 
of ROS production in the cell and therefore the prime targets for oxidative damage ${ }^{(4)}$. Superoxide may spontaneously dismute, or the dismutation may be catalysed by superoxide dismutase (SOD), forming $\mathrm{H}_{2} \mathrm{O}_{2}$. This can cause oxidative damage to the surrounding biomolecules, as, in the presence of ferrous $\mathrm{Fe}, \mathrm{H}_{2} \mathrm{O}_{2}$ may react to form the highly reactive hydroxyl radical, via Fenton chemistry.

In order to combat the effects of ROS, aerobic organisms have developed an extensive antioxidant defence system, which include both non-enzymatic and enzymatic antioxidants. Enzymatic antioxidants include SOD, glutathione peroxidase $(\mathrm{GPx})$ and catalase ${ }^{(5)}$, whereas non-enzymatic antioxidants are represented by vitamin $\mathrm{C}$, vitamin $\mathrm{E}$, thiol antioxidants (glutathione and lipoic acid) and other antioxidants ${ }^{(6)}$. However, when these ROS are chronically produced at high rates, they may overwhelm non-enzymatic and enzymatic antioxidant systems. As a result, ROS could then cause deleterious effects by inducing the irreversible oxidation of their principal targets such as DNA, lipids and proteins ${ }^{(7)}$, leading to oxidative damage and cell death.

Oxidative damage to the mitochondria has been proposed to cause a wide range of metabolic disorders including Parkinson's disease $^{(8,9)}$, Huntington's disease ${ }^{(10)}$, Alzheimer's disease ${ }^{(11,12)}$, diabetes $^{(13)}$, obesity $^{(14)}$, fatty liver ${ }^{(15)}$ and ageing ${ }^{(16,17)}$. For the last three decades, antioxidant therapy has been intensively studied to prevent or treat these oxidative stress-associated diseases. Although antioxidants such as vitamin E, ubiquinol and $N$-acetylcysteine have previously been reported to decrease mitochondrial ROS concentrations and consequently alleviate mitochondrial oxidative damage ${ }^{(18-20)}$, their effectiveness still seems to be largely limited by their poor capacity to accumulate specifically within the mitochondria.

Recently, Murphy and co-workers ${ }^{(21,22)}$ developed a series of mitochondria-targeted antioxidants by conjugation with triphenylphosphonium cations, which can permeate lipid bilayers easily and accumulate 100- to 1000-fold within the mitochondria. One of these mitochondria-targeted antioxidants is a mitochondria-targeted vitamin $\mathrm{E}$ derivative (MitoVit E), which has been tested in a wide range of mitochondrial and cell models. Indeed, it has been shown to mitigate ethanol-induced suppression of antioxidant defence systems in cerebellar granule cells ${ }^{(23)}$, inhibit peroxide-induced apoptosis in endothelial cells ${ }^{(24)}$ and prevent cell death in Friedreich's ataxia fibroblasts ${ }^{(25)}$. However, to our knowledge, the effect of MitoVit $\mathrm{E}$ on mitochondrial alterations and systemic oxidative stress has never been studied in vivo. In order to investigate this further, we investigated the effects of MitoVit E on mitochondrial ATP and $\mathrm{H}_{2} \mathrm{O}_{2}$ production rates, mitochondrial size and number, urinary isoprostane concentration, and some plasma redox biomarkers in C57BL/6 mice.

\section{Materials and methods}

\section{Chemicals}

MitoVit E was synthesised with the starting material benzopyran-6-ol acetate, which was prepared in one step from commercially available chemicals as reported by Ichikawa \&
Kato ${ }^{(26)}$. Benzopyran-6-ol acetate was oxidised using ozone in methylene chloride-methanol at $-78^{\circ} \mathrm{C}$. The resulting solution was purged with Ar to remove excess ozone and then treated directly with sodium borohydride to produce an alcohol similar to that in the scientific literature ${ }^{(26,27)}$. The alcohol was converted to MitoVit E as reported by Grisar et al. ${ }^{(28)}$. Briefly, the alcohol was treated with iodine, triphenylphosphine and imidazole in methylene chloride at $0^{\circ} \mathrm{C}$ for $3 \mathrm{~h}$ to obtain a $92 \%$ iodide yield. The iodide was treated with triphenylphosphine in acetonitrile at reflux for $11 \mathrm{~h}$ to produce the phosphonium salt as a crystalline solid in quantitative yield. The product of MitoVit E was $>95 \%$ pure as evidenced by TLC and NMR.

All the other chemicals used in the present study were obtained from Sigma-Aldrich (St Louis, MO, USA), unless otherwise stated.

\section{Animals and study design}

A total of sixty-four 7-week-old C57BL/6 male mice (Jackson Laboratory, Bar Harbor, ME, USA) were divided into four blocks and arrived at four different times. Mice were housed one per cage in a temperature-controlled $\left(18-22^{\circ} \mathrm{C}\right)$ and light-controlled environment with a $12 \mathrm{~h}$ light- $12 \mathrm{~h}$ dark cycle. Mice were fed a high-fat (HF) diet for 5 weeks and then switched to either a low-fat (LF) diet or a medium-fat (MF) diet, and administered orally with MitoVit E ( $40 \mathrm{mg}$ MitoVit $\mathrm{E} / \mathrm{kg}$ body weight) or drug vehicle $(10 \%(\mathrm{v} / \mathrm{v})$ ethanol in $0.9 \%$ $(\mathrm{w} / \mathrm{v}) \mathrm{NaCl}$ solution), every other day for 5 weeks. Detailed compositions of the HF, MF and LF diets are provided in Table S1 of the supplementary material (available online at http://www.journals.cambridge.org/bjn). All mice in the four groups (LF group receiving drug vehicle, LF-C; LF group receiving MitoVit E, LF-E; MF group receiving drug vehicle, MF-C; MF group receiving MitoVit $\mathrm{E}, \mathrm{MF}-\mathrm{E}$ ) had unrestricted access to feed and water. During the study, urine was collected for isoprostane and creatinine assays. At the end of the study, all mice were killed by exposure to $\mathrm{CO}_{2}$ in a gas chamber. Blood was collected by cardiac puncture for biochemical assays in the plasma. The gastrocnemius and liver from eight mice of each group were rapidly excised for mitochondrial isolation and subsequent measurements of ATP and $\mathrm{H}_{2} \mathrm{O}_{2}$ production rates in the mitochondria. The soleus muscles from two mice of each group were used in transmission electron microscopy for quantification of mitochondrial number and average size. Institutional and national guidelines for the care and use of animals were followed, and all experimental procedures involving animals were approved by the Institutional Animal Care and Use Committee of Iowa State University.

\section{Mitochondrial preparation from the liver and skeletal muscle}

Liver mitochondria were isolated at $4^{\circ} \mathrm{C}$, as described previously by Cawthon et al. ${ }^{(29)}$, with some modifications. Briefly, liver tissue $(0.5 \mathrm{~g})$ was homogenised using a Potter-Elvehjem glass homogeniser (Omni International, Kennesaw, GA, USA) in $10 \mathrm{ml}$ iced extraction buffer (10 mM-HEPES, $200 \mathrm{~mm}$-mannitol, 
$70 \mathrm{~mm}$-sucrose, $1 \mathrm{~mm}$-ethylene glycol tetra-acetic acid and bovine serum albumin ( $2 \mathrm{~g} / \mathrm{l})$, $\mathrm{pH} 7 \cdot 5)$. Homogenates were centrifuged at $600 \mathrm{~g}$ for $8 \mathrm{~min}$, and the supernatants were filtered through a double layer of cheesecloth followed by centrifugation at $11000 \mathrm{~g}$ for $12 \mathrm{~min}$. The pellet was resuspended in $20 \mathrm{ml}$ extraction buffer without bovine serum albumin and centrifuged at $600 \mathrm{~g}$ for $8 \mathrm{~min}$. The supernatants were centrifuged at $11000 \mathrm{~g}$ for $12 \mathrm{~min}$ to get the final mitochondrial pellets for subsequent analyses.

Skeletal muscle mitochondria were isolated at $4{ }^{\circ} \mathrm{C}$, as described previously by Chappell \& Perry ${ }^{(30)}$, with slight modifications. The gastrocnemius was minced with scissors in Chappell-Perry Medium I (100 mm-KCl, $50 \mathrm{~mm}-$ Tris- $\mathrm{HCl}$,

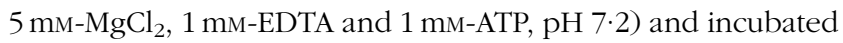
in 20 vol. of Chappell-Perry Medium I supplemented with Nagarse $(150 \mathrm{mg} / \mathrm{l}$; Sigma-Aldrich) for $10 \mathrm{~min}$. The muscles were then homogenised at $4^{\circ} \mathrm{C}$ with a Potter-Elvehjem glass homogeniser (Omni International). After the homogenate was centrifuged at $600 \boldsymbol{g}$ for $10 \mathrm{~min}$, the supernatant was filtered through a double layer of cheesecloth and centrifuged at $14000 \mathrm{~g}$ for $10 \mathrm{~min}$. The pellets were resuspended in modified Chappell-Perry II buffer (100 mM-KCl, $50 \mathrm{~mm}$-Tris- $\mathrm{HCl}$,

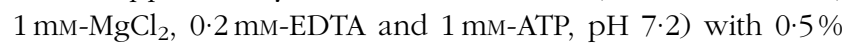
$(\mathrm{w} / \mathrm{v})$ bovine serum albumin and centrifuged at $7000 \mathrm{~g}$ for $10 \mathrm{~min}$. The pellets were resuspended in modified ChappellPerry II buffer without bovine serum albumin and centrifuged at $3500 \mathbf{g}$ for $10 \mathrm{~min}$; this step was repeated twice. Mitochondrial pellets were used for subsequent analyses.

\section{Determination of ATP and hydrogen peroxide production} rates in the mitochondria

ATP production rate was measured, as described previously by Mansouri et al. ${ }^{(31)}$. Reactions were conducted in ninetysix-well microplates with a $100 \mu \mathrm{l}$ reaction system ( $25 \mathrm{~mm}$-Tricine,

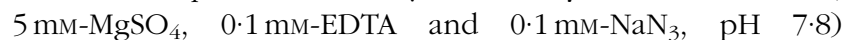
containing $100 \mu \mathrm{g}$ of mitochondrial protein, substrates (1 mm-glutamate plus $1 \mathrm{~mm}$-malate), ADP $(0.025 \mathrm{mmol} / \mathrm{l})$ and luciferase reagent (Roche, Madison, WI, USA). Luminescence was recorded by the Synergy ${ }^{\mathrm{TM}} 2$ Multi-Mode microplate reader (BioTek Instruments, Winooski, VT, USA) every $36 \mathrm{~s}$ for a total of $6 \mathrm{~min}$. The slope of increase within the linear portion of the curve was used for the ATP production rate.

Mitochondrial $\mathrm{H}_{2} \mathrm{O}_{2}$ production rate was measured by using Amplex $^{\mathrm{TM}}$ Red-horseradish peroxidase ( $N$-acetyl-3,7-dihydroxyphenoxazine; Invitrogen, Carlsbad, CA, USA), as described previously by Muller et $a l^{(32)}$. Sample reactions were conducted in ninety-six-well microplates with a $100 \mu \mathrm{l}$ reaction system $\left(125 \mathrm{~mm}-\mathrm{KCl}, 10 \mathrm{~mm}-\mathrm{HEPES}, 2 \mathrm{~mm}-\mathrm{K}_{2} \mathrm{HPO}_{4}\right.$

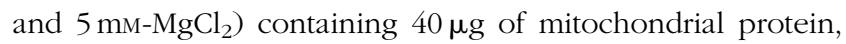
substrate (9 mm-succinate), CuZnSOD (100000 units/1), Amplex $^{\mathrm{TM}}$ Red reagent $(80 \mu \mathrm{mol} / \mathrm{l})$ and horseradish peroxidase (1000 units/1). Fluorescence was recorded at an excitation wavelength of $530 \mathrm{~nm}$ and an emission wavelength of $590 \mathrm{~nm}$ on the Synergy ${ }^{\mathrm{TM}} 2$ Multi-Mode microplate reader (BioTek Instruments) every $36 \mathrm{~s}$ for a total of $10 \mathrm{~min}$. The slope of increase within the linear portion of the curve was used for the $\mathrm{H}_{2} \mathrm{O}_{2}$ production rate.
For the two aforementioned assays, sample blanks contained all components in the reaction system except mitochondrial protein. The slopes of the increase in the blanks were subtracted from the slopes of the increase in the samples. The results for ATP and $\mathrm{H}_{2} \mathrm{O}_{2}$ production rates were analysed by Gen5 (BioTek Instruments).

\section{Measurement of mitochondrial size and number}

Soleus muscle was excised from mice and immediately immersed in a cold $\left(4^{\circ} \mathrm{C}\right)$ primary fixative consisting of $2 \%$ $(\mathrm{w} / \mathrm{v})$ glutaraldehyde and $2 \%(\mathrm{w} / \mathrm{v})$ paraformaldehyde in a $0 \cdot 1 \mathrm{M}$-cacodylate buffer at $\mathrm{pH} 7 \cdot 24$. The muscle was sliced into smaller pieces in the fixative and stored overnight at $4^{\circ} \mathrm{C}$. The pieces were washed in cold buffer (three times, $20 \mathrm{~min}$ each) and placed into $1 \%(\mathrm{w} / \mathrm{v}) \mathrm{OsO}_{4}$ in the same buffer for $1 \mathrm{~h}$. After this secondary fixation, the pieces were washed several times in the buffer, placed into $2 \%(\mathrm{w} / \mathrm{v}) \mathrm{aqu}-$ eous uranyl acetate for $1 \mathrm{~h}$ and dehydrated through an ethanol series to pure ethanol and ultra-pure ethanol before infiltration with increasing concentrations of Embed 812 resin mixture to pure resin mixture. Pieces were embedded in moulds and polymerised at $60^{\circ} \mathrm{C}$ for $24 \mathrm{~h}$. The pieces were sectioned ( $1 \mu \mathrm{m}$ thick) with glass knives using a Leica-Reichert ultramicrotome (www.leica.com) to determine orientation and location. Thin sections $(60-90 \mathrm{~nm})$ thick were cut with a diamond knife and placed on 200 mesh $\mathrm{Cu}$ grids. Images were made using a JEOL 2100 TEM (www.jeol.com) set at a magnification $(4000 \times)$ with a bar scale on each image. The images were transferred into an SIS Analysis (Olympus, Münster, Germany; www.soft-imaging.net) program that calculated mitochondrial number and individual area.

\section{Measurement of urinary isoprostane and creatinine}

Urine samples were thawed at room temperature and vortexed vigorously before analysis. Urinary 8-iso-PGF2 $\alpha$ was determined using a commercially available ELISA kit from Oxford Biomedical Research (Oxford, MI, USA). Internal controls were run on every plate to adjust the plate differences. Urinary creatinine was quantified with a commercial kit from Cayman Chemical (Ann Arbor, MI, USA) using a method based on the reaction of creatinine and alkaline picrate according to the manufacturer's instructions. Results of urinary isoprostane were normalised by urinary creatinine.

\section{Measurement of redox parameters in the plasma}

Activities of plasma SOD and GPx were measured using kits from Cayman Chemical. Plasma $\mathrm{H}_{2} \mathrm{O}_{2}$ concentration was measured using an Amplex Red hydrogen peroxide assay kit from Invitrogen.

\section{Determination of protein concentration}

Protein concentration was measured using the Bradford $\operatorname{method}^{(33)}$. 


\section{Statistical analysis}

Data were analysed by ANOVA using a general randomised complete block design, with each of the four different arrival times considered as a block. Block, diet, MitoVit E and their interaction were the fixed effects in the model. SAS Proc Mixed (SAS, 2005; SAS Institute, Cary, NC, USA) was used to compute the ANOVA table, least-squares means and differences between the least-squares means. A block effect representing differences between the four blocks could be attributed to many factors (e.g. four blocks of mice were different, or assay reagents or set-ups in the four individual experiments were different). The block effect is not discussed in the present study, but it has to be ruled out for correctly evaluating the effects of the MF diet and MitoVit E. Data are presented as means with their standard errors. Differences between groups were considered to be significant at $P<0.05$.

\section{Results}

\section{Levels of urinary isoprostane and mouse body weight} before treatments

Isoprostanes are a unique series of PG-like compounds formed in vivo from the free radical-catalysed peroxidation of arachidonic acid independent of cyclo-oxygenase enzymes $^{(34)}$. The quantification of plasma or urinary $\mathrm{F}_{2}$-isoprostanes has been regarded as one of the most accurate methods to assess in vivo oxidant stress status when compared with other biomarkers ${ }^{(35)}$. Levels of urinary isoprostane increased 6- and 7.5-fold, respectively, after 2 and 4 weeks of HF feeding before either drug vehicle or MitoVit E administration (Fig. 1(a)). Body weight also increased significantly $(P<0.05)$ during this period (Fig. 1(b)).

\section{Mitochondrial ATP and hydrogen peroxide production} rates

In both the liver and muscle, ATP and $\mathrm{H}_{2} \mathrm{O}_{2}$ production rates were not affected by either MitoVit $\mathrm{E}$ administration or the MF diet when succinate was used as the substrate (Table 1). ATP production rate in the muscle mitochondria was almost as

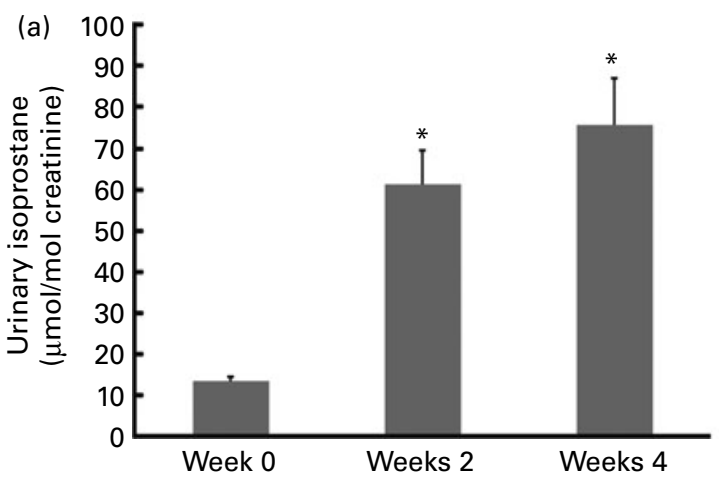

twentyfold high as that in the liver mitochondria, whereas $\mathrm{H}_{2} \mathrm{O}_{2}$ production rate in the liver mitochondria was as tenfold high as that in the muscle mitochondria (Table 1).

\section{Measurement of mitochondrial number and size}

The number and average size of the intermyofibrillar mitochondria were not affected by MitoVit E treatment in either LF or MF diet-fed mice (Table 2). However, the number and average size of the subsarcolemmal mitochondria were fourand twofold higher in MF-E mice than in MF-C mice, respectively $(P<0.05)$. Conversely, the number of intermyofibrillar and subsarcolemmal mitochondria was significantly decreased in the MF-C group compared with the LF-C group (Table 2). In addition, there was a diet $\times$ MitoVit $E$ interaction effect for the number of subsarcolemmal mitochondria $(P=0.035)$. The representative transmission electron microscopic images of subsarcolemmal and intermyofibrillar mitochondria from the soleus muscle of LF-C, LF-E, MF-C and MF-E mice are shown in Fig. 2, where arrows indicate mitochondria. Remarkably, in the MF-C group, very few intermyofibrillar mitochondria were observed, and subsarcolemmal mitochondria had an increased number of disarrayed cristae and a reduced electron density of the matrix. By contrast, MitoVit E administration increased the mitochondrial number and electron density in MF diet-fed mice.

\section{Measurement of urinary isoprostane after treatments}

After 2 and 4 weeks of HF feeding, urinary isoprostane concentration increased four- and fivefold, respectively (Fig. 1(a)). However, after the mice were switched from the HF diet to either the LF or the MF diet with or without MitoVit $\mathrm{E}$, urinary isoprostane concentration decreased in the first week (week 6) immediately (Table 3). The levels of the decreased urinary isoprostane after the first week (week 6) were maintained for the rest of the study (weeks 7-10) for all four groups (Table 3). The administration of MitoVit E significantly enhanced the decrease in urinary isoprostane in LF diet-fed mice (LF-C $v$. LF-E) for the whole study, but not in MF diet-fed mice (MF-C $v$. MF-E) except at week 6 (Table 3).

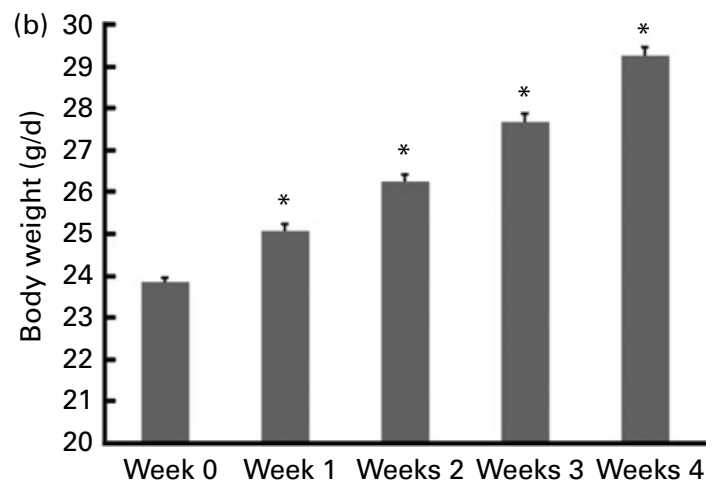

Fig. 1. (a) Urinary isoprostane concentration of mice in the first 4 weeks when fed a high-fat (HF) diet ( $n$ 48). Urinary isoprostane was normalised by urinary creatinine ( $\mu \mathrm{mol} / \mathrm{mol}$ creatinine). (b) Body weight of mice in the first 4 weeks when fed a HF diet ( $\mathrm{g} / \mathrm{d}, n$ 64). Values are means, with standard errors represented by vertical bars. * Mean values were significantly different from those of week $0(P<0.05)$. 
Table 1. ATP and hydrogen peroxide production rates in the liver and muscle mitochondria of low-fat diet-fed mice receiving drug vehicle (LF-C), lowfat diet-fed mice receiving mitochondria-targeted vitamin E derivative (MitoVit E) (LF-E), medium-fat diet-fed mice receiving drug vehicle (MF-C) and medium-fat diet-fed mice receiving MitoVit E (MF-E)

(Mean values with their standard errors for seven to eight mice per group)

\begin{tabular}{|c|c|c|c|c|c|c|c|c|c|c|c|c|}
\hline & \multicolumn{2}{|c|}{ LF-C } & \multicolumn{2}{|c|}{ LF-E } & \multicolumn{2}{|c|}{ MF-C } & \multicolumn{2}{|c|}{ MF-E } & \multicolumn{4}{|c|}{ ANOVA $(P)^{*}$} \\
\hline & Mean & SEM & Mean & SEM & Mean & SEM & Mean & SEM & Block & Diet & MitoVit E & Diet $\times$ MitoVit $E$ \\
\hline \multicolumn{13}{|c|}{ ATP production rate (nmol/min per $\mathrm{mg}$ protein) } \\
\hline Liver & 0.360 & 0.050 & 0.350 & 0.048 & 0.320 & 0.026 & 0.390 & 0.029 & 0.977 & 0.976 & 0.419 & 0.333 \\
\hline Muscle & $6 \cdot 187$ & $1 \cdot 310$ & $5 \cdot 320$ & $1 \cdot 229$ & 4.943 & $1 \cdot 182$ & $6 \cdot 033$ & $1 \cdot 148$ & $0 \cdot 153$ & 0.909 & 0.990 & 0.364 \\
\hline \multicolumn{13}{|c|}{$\mathrm{H}_{2} \mathrm{O}_{2}$ production rate ( $\mathrm{nmol} / \mathrm{min}$ per $\mathrm{mg}$ protein) } \\
\hline Liver & 0.146 & 0.011 & 0.138 & 0.046 & 0.166 & 0.016 & 0.152 & 0.012 & 0.226 & 0.173 & 0.349 & 0.816 \\
\hline Muscle & 0.015 & 0.002 & 0.014 & 0.005 & 0.016 & 0.002 & 0.016 & 0.006 & 0.054 & 0.481 & 0.322 & 0.222 \\
\hline
\end{tabular}

*Values of ANOVA $(P)$ are $P$ values for block effect and main effects, such as diet, MitoVit $\mathrm{E}$ and interaction between diet and MitoVit $\mathrm{E}$ in the LF-C, LF-E, MF-C and MF-E groups.

In addition, the decrease in urinary isoprostane was significantly higher in the LF-E group than in the other three groups during the whole study (weeks 6-10), indicating that the combination of LF diet and MitoVit $\mathrm{E}$ administration is most effective in decreasing systemic oxidative stress.

\section{Measurement of redox parameters in the plasma}

Plasma SOD activity was lower in the MF-C group than in the LF-C group $(P<0 \cdot 05)$. Plasma GPx activity was also significantly decreased in the MF-E group compared with the LF-E group (Table 4). Concentrations of plasma $\mathrm{H}_{2} \mathrm{O}_{2}$ in the LF-C and LF-E groups were significantly lower than in the MF-C and MF-E groups, respectively (Table 4). A significant increase in plasma SOD activity was observed in MF-E group when compared with the MF-C group. In addition, there was a diet $X$ MitoVit E interaction effect for plasma SOD activity $(P=0.038)$.

\section{Discussion}

Our oxidative stress model was established by feeding mice a HF diet for 5 weeks to induce higher oxidative stress, which was indicated by the increase in urinary isoprostane (Fig. 1(a)). Cumulative evidence strongly suggests that elevated oxidative stress is associated with obesity development ${ }^{(36-39)}$. This suggestion has been confirmed by our observations that urinary isoprostanes increased with increased body weight during the first 4 weeks of HF feeding (Fig. 1(a) and (b)).

Mitochondrial ATP production rate was not affected by MitoVit E in either the liver or the gastrocnemius. This observation was confirmed by using different combinations of substrates for measuring the mitochondrial ATP production rates, such as glutamate plus malate in the present study, glutamate plus malate plus palmitoyl-L-carnitine ${ }^{(40)}$ and glutamate plus malate plus palmitoyl-L-carnitine plus $\alpha$-ketoglutarate (G Mao, GA Kraus, I Kim, ME Spurlock, TB Bailey and DC Beitz, unpublished results).

No effects of MitoVit $\mathrm{E}$ on mitochondrial $\mathrm{H}_{2} \mathrm{O}_{2}$ production rate were observed in the present study when succinate was used as the substrate. However, when glutamate plus malate was used as the substrate, MitoVit E in the same study significantly decreased the mitochondrial $\mathrm{H}_{2} \mathrm{O}_{2}$ production in the liver but not in the muscle of MF diet-fed mice ${ }^{(40)}$, indicating that the effect of MitoVit $\mathrm{E}$ on scavenging mitochondriaderived ROS might be substrate-dependent and thus complex-dependent.

In addition, the capacity of MitoVit $\mathrm{E}$ in reducing the mitochondrial oxidative damage has been confirmed by our observation that it significantly reduced protein carbonyl in the liver mitochondria of MF-E mice compared with MF-C mice ${ }^{(40)}$, which is consistent with the previous finding that MitoVit $\mathrm{E}$

Table 2. Mitochondrial number and average size in the soleus muscle of low-fat diet-fed mice receiving drug vehicle (LF-C), low-fat diet-fed mice receiving mitochondria-targeted vitamin $\mathrm{E}$ derivative (MitoVit E) (LF-E), medium-fat diet-fed mice receiving drug vehicle (MF-C) and medium-fat diet-fed mice receiving MitoVit $\mathrm{E}$ (MF-E) mice

(Mean values with their standard errors, analysis of five images per mouse and two mice per group)

\begin{tabular}{|c|c|c|c|c|c|c|c|c|c|c|c|}
\hline & \multicolumn{2}{|c|}{ LF-C } & \multicolumn{2}{|c|}{ LF-E } & \multicolumn{2}{|c|}{ MF-C } & \multicolumn{2}{|c|}{ MF-E } & \multicolumn{3}{|c|}{$\operatorname{ANOVA}(P)^{*}$} \\
\hline & Mean & SEM & Mean & SEM & Mean & SEM & Mean & SEM & Diet & MitoVit E & Diet $\times$ MitoVit $E$ \\
\hline \multicolumn{12}{|c|}{ Number of mitochondria (number/section) } \\
\hline Intermyofibrillar mitochondria & $17 \cdot 7^{\mathrm{c}}$ & 3.7 & $16 \cdot 3^{b, c}$ & $2 \cdot 3$ & $5 \cdot 7^{\mathrm{a}}$ & 1.7 & $7 \cdot 3^{\mathrm{a}, \mathrm{b}}$ & $1 \cdot 1$ & 0.012 & 0.969 & 0.566 \\
\hline Subsarcolemmal mitochondria & $23 \cdot 1^{c}$ & 1.7 & $25 \cdot 7^{\mathrm{c}}$ & $2 \cdot 7$ & $3.0^{\mathrm{a}}$ & 0.6 & $15 \cdot 9^{\mathrm{b}}$ & 0.1 & $<0.001$ & 0.009 & 0.035 \\
\hline \multicolumn{12}{|c|}{ Average of mitochondrial size $\left(\mu \mathrm{m}^{2}\right)$} \\
\hline Intermyofibrillar mitochondria & 0.123 & 0.023 & 0.126 & 0.056 & 0.076 & 0.018 & 0.104 & 0.006 & 0.342 & 0.651 & 0.716 \\
\hline Subsarcolemmal mitochondria & $0 \cdot 305^{\mathrm{a}, \mathrm{b}}$ & 0.016 & $0.397^{b}$ & 0.015 & $0.125^{\mathrm{a}}$ & 0.003 & $0.387^{b}$ & 0.113 & 0.172 & 0.037 & 0.212 \\
\hline
\end{tabular}

${ }^{a, b, c}$ Mean values within a row with unlike superscript letters were significantly different $(P<0.05)$.

${ }^{*}$ Values of ANOVA $(P)$ are $P$ values for main effects, such as diet, MitoVit E and interaction between diet and MitoVit E in the LF-C, LF-E, MF-C and MF-E groups. There is no block effect in the ANOVA model because all the mice $(n)$ for microscopy are from the same block. 

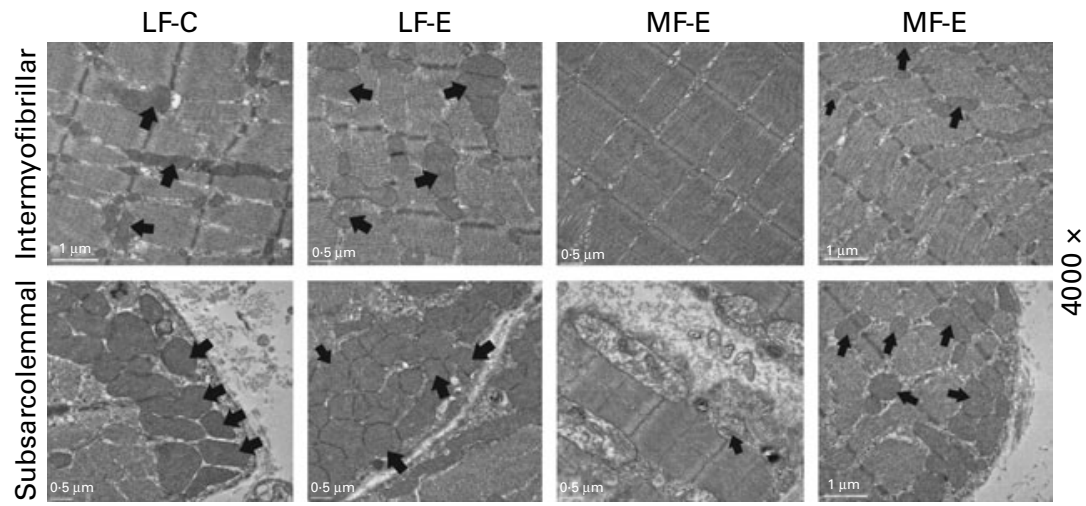

Fig. 2. Representative transmission electron microscopic images (original magnification, $4000 \times$ ) of subsarcolemmal and intermyofibrillar mitochondria from the soleus muscle of low-fat diet-fed mice receiving drug vehicle (LF-C), low-fat diet-fed mice receiving mitochondria-targeted vitamin E derivative (MitoVit E) (LF-E), medium-fat diet-fed mice receiving drug vehicle (MF-C) and medium-fat diet-fed mice receiving MitoVit E (MF-E). Arrows indicate mitochondria.

protected liver mitochondria from Fe/ascorbate-induced oxidative damage by decreasing protein carbonyl ${ }^{(41)}$.

A previous study has found that in a diabetic mouse model after 16 weeks of HF, high-sucrose feeding, the number and size of both subsarcolemmal and intermyofibrillar mitochondria in the skeletal muscle decreased along with a significant increase in ROS production ${ }^{(42)}$. The same study also reported that mice treated with streptozotocin, a well-known model of hyperglycaemia-associated oxidative stress without insulin resistance and obesity, significantly decreased the mitochondrial number, whereas $N$-acetylcysteine treatment of these streptozotocin mice restored the mitochondrial density, indicating that mitochondrial number and size might be altered by oxidative stress. In addition, a decrease in mitochondrial size and number has also been reported in the neurons of patients with Alzheimer's disease ${ }^{(43)}$, the pathogenesis of which has been extensively attributed to mitochondrial oxidative damage and dysfunction ${ }^{(44)}$.

Consistent with this concept, the present results showed that the MF diet decreased the number of intermyofibrillar and subsarcolemmal mitochondria in the soleus muscle, whereas MitoVit $\mathrm{E}$ increased the number and size of the subsarcolemmal mitochondria. However, why MitoVit E only has the effect on the subsarcolemmal but not on the intermyofibrillar mitochondria still remains elusive. Combined with $\mathrm{H}_{2} \mathrm{O}_{2}$ production rate data in the gastrocnemius though, another question arises: why did MitoVit $\mathrm{E}$ have no effect on mitochondrial $\mathrm{H}_{2} \mathrm{O}_{2}$ production rate in the gastrocnemius, but it could still increase the size and number of subsarcolemmal mitochondria in the soleus? We could not exclude the possibility that MitoVit E might affect the subsarcolemmal mitochondrial density by some other unknown properties other than as an antioxidant. Alternatively, this question could also have to do with the different fibre types in the two muscles (red oxidative soleus $v$. white glycolytic gastrocnemius). The precise mechanism still remains unclear until the effects of MitoVit $\mathrm{E}$ on the mitochondrial density in the gastrocnemius and the mitochondrial $\mathrm{H}_{2} \mathrm{O}_{2}$ production rate in the soleus muscle are investigated in the future.

Clinically, one of the keys to success in the diagnosis and management of those oxidative damage-induced metabolic disorders is the utilisation of those easily accessible plasmaand urine-based biomarkers for the objective assessment of oxidative stress and response to therapeutics.

In the present study, urinary isoprostane was used as a systematic oxidative stress marker. To our knowledge, the effect

Table 3. Decrease in urinary isoprostane from low-fat diet-fed mice receiving drug vehicle (LF-C), low-fat diet-fed mice receiving mitochondria-targeted vitamin E derivative (MitoVit E) (LF-E), medium-fat diet-fed mice receiving drug vehicle (MF-C) and medium-fat diet-fed mice receiving MitoVit $\mathrm{E}$ $($ MF-E)*

(Mean values with their standard errors for six mice per group)

\begin{tabular}{|c|c|c|c|c|c|c|c|c|c|c|c|c|}
\hline & \multicolumn{2}{|c|}{ LF-C } & \multicolumn{2}{|c|}{ LF-E } & \multicolumn{2}{|c|}{ MF-C } & \multicolumn{2}{|c|}{ MF-E } & \multicolumn{4}{|c|}{ ANOVA $(P) \dagger$} \\
\hline & Mean & SEM & Mean & SEM & Mean & SEM & Mean & SEM & Block & Diet & MitoVit E & Diet $\times$ MitoVit $E$ \\
\hline \multicolumn{13}{|c|}{ Decrease in urinary isoprostane $(\mu \mathrm{mol} / \mathrm{mol}$ creatinine $)$} \\
\hline Week 6 & $36 \cdot 38^{\mathrm{b}}$ & 4.59 & $62 \cdot 98^{\mathrm{c}}$ & $7 \cdot 34$ & $21 \cdot 40^{\mathrm{a}}$ & 3.66 & $38 \cdot 41^{\mathrm{b}}$ & 3.96 & 0.339 & $<0.001$ & $<0.001$ & 0.321 \\
\hline Week 7 & $34.66^{\mathrm{a}}$ & $5 \cdot 79$ & $60 \cdot 86^{\mathrm{b}}$ & $7 \cdot 88$ & $19 \cdot 82^{\mathrm{a}}$ & 4.25 & $35 \cdot 36^{\mathrm{a}}$ & 3.02 & 0.093 & $<0.001$ & 0.001 & 0.261 \\
\hline Week 8 & $34.52^{\mathrm{a}}$ & $5 \cdot 80$ & $59 \cdot 68^{\mathrm{b}}$ & 8.47 & $21.54^{\mathrm{a}}$ & 3.50 & $30 \cdot 71^{\mathrm{a}}$ & 8.96 & 0.039 & 0.003 & 0.023 & 0.170 \\
\hline Week 9 & $35 \cdot 28^{\mathrm{a}}$ & $4 \cdot 30$ & $57 \cdot 89^{\mathrm{b}}$ & $6 \cdot 65$ & $22 \cdot 11^{\mathrm{a}}$ & 3.28 & $35 \cdot 13^{\mathrm{a}}$ & 4.93 & 0.235 & 0.001 & 0.002 & 0.293 \\
\hline Week 10 & $28 \cdot 23^{\mathrm{a}}$ & 5.57 & $57.75^{\mathrm{b}}$ & $8 \cdot 30$ & $19 \cdot 48^{\mathrm{a}}$ & 4.42 & $32 \cdot 72^{\mathrm{a}}$ & 4.02 & 0.085 & 0.005 & 0.002 & 0.121 \\
\hline
\end{tabular}

${ }^{a, b, c}$ Mean values within a row with unlike superscript letters were significantly different $(P<0.05)$.

* Urinary isoprostane was normalised by urinary creatinine, and decrease in urinary isoprostane was calculated by subtracting the levels of urinary isoprostane at weeks 6 , 7 , 8,9 and 10 from the baseline level of urinary isoprostane at week 5 , respectively.

†Values of ANOVA $(P)$ are $P$ values for block effect and main effects, such as diet, MitoVit $\mathrm{E}$ and interaction between diet and MitoVit $\mathrm{E}$ in the LF-C, LF-E, MF-C and MF-E groups. 
Table 4. Plasma parameters of low-fat diet-fed mice receiving drug vehicle (LF-C), low-fat diet-fed mice receiving mitochondria-targeted vitamin $E$ derivative (MitoVit E) (LF-E), medium-fat diet-fed mice receiving drug vehicle (MF-C) and medium-fat diet-fed mice receiving MitoVit $E$ (MF-E)* (Mean values with their standard errors for seven to ten mice per group)

\begin{tabular}{|c|c|c|c|c|c|c|c|c|c|c|c|c|}
\hline & \multicolumn{2}{|c|}{ LF-C } & \multicolumn{2}{|c|}{ LF-E } & \multicolumn{2}{|c|}{ MF-C } & \multicolumn{2}{|c|}{ MF-E } & \multicolumn{4}{|c|}{ ANOVA $(P) \dagger$} \\
\hline & Mean & SEM & Mean & SEM & Mean & SEM & Mean & SEM & Block & Diet & MitoVit E & Diet $\times$ MitoVit E \\
\hline \multicolumn{13}{|c|}{ Plasma parameters (fold of LF-C) } \\
\hline SOD & $1.000^{\mathrm{b}}$ & 0.034 & $1.014^{\mathrm{b}}$ & 0.049 & $0.904^{\mathrm{a}}$ & 0.036 & $1.051^{b}$ & 0.016 & 0.004 & 0.340 & 0.014 & 0.038 \\
\hline GPx & $1.000^{\mathrm{a}, \mathrm{b}}$ & 0.050 & $1 \cdot 129^{b}$ & 0.120 & $0.977^{\mathrm{a}, \mathrm{b}}$ & 0.038 & $0.877^{\mathrm{a}}$ & 0.043 & 0.112 & 0.058 & 0.839 & 0.109 \\
\hline $\mathrm{H}_{2} \mathrm{O}_{2}$ & $1.000^{\mathrm{a}, \mathrm{b}}$ & 0.063 & $0.897^{\mathrm{a}}$ & 0.044 & $1 \cdot 207^{c}$ & 0.087 & $1 \cdot 144^{\mathrm{b}, \mathrm{c}}$ & 0.045 & 0.509 & 0.001 & 0.279 & 0.690 \\
\hline
\end{tabular}

SOD, superoxide dismutase; GPx, glutathione peroxidase.

a,b,c Mean values within a row with unlike superscript letters were significantly different $(P<0.05)$

${ }^{*}$ Mean values are fold changes relative to the LF-C group set to 1 unit.

† Values of ANOVA $(P)$ are $P$ values for block effect and main effects, such as diet, MitoVit $\mathrm{E}$ and interaction between diet and MitoVit $\mathrm{E}$ in the LF-C, LF-E, MF-C and MF-E groups.

of MitoVit E on plasma or urinary isoprostanes has never been studied before. However, there are several studies available in the literature for the effect of non-targeted vitamin $\mathrm{E}$ on the isoprostanes, even though their results are not consistent. Both $\alpha$-tocopherol and mixed tocopherol supplementation resulted in reduced plasma isoprostanes but did not affect $24 \mathrm{~h}$ urinary isoprostanes in patients with type 2 diabetes ${ }^{(45)}$. However, in the patients with coronary disease, high-dose $\alpha$-tocopherol supplementation significantly reduced urinary isoprostanes $^{(46)}$. By contrast, vitamin E supplementation failed to decrease urinary isoprostanes in either lean or obese mice ${ }^{(47)}$.

The present results indicate that MitoVit E decreased urinary isoprostanes, and its effect was more significant in LF diet-fed mice than in MF diet-fed mice, which could be attributed to the fact that the decrease in urinary isoprostane concentration in the LF-E group was significantly higher than in the other three groups (LF-C, MF-C and MF-E).

Decrease in antioxidant status leading to the generation of oxidative stress may play an important role in the pathogenesis of oxidative stress-induced metabolic disorders ${ }^{(48)}$. Indeed, decreased activities of plasma SOD and GPx were commonly observed in different models of oxidative stress, whereas antioxidant treatments normalised their activities $^{(49-51)}$.

Consistently, the present results indicate that the MF diet significantly decreased plasma SOD and GPx activities and thus increased plasma $\mathrm{H}_{2} \mathrm{O}_{2}$ concentration when compared with the LF diet. However, in the present study, MitoVit E only increased the activity of plasma SOD but not the activity of plasma GPx. Similar observations were found in a lipopolysaccharide-induced oxidative stress model in the rat liver ${ }^{(50)}$. Lipopolysaccharide treatment significantly decreased hepatic antioxidant enzyme activities such as SOD and GPx, whereas pre-treatment with resveratrol, a polyphenol with antioxidant properties abundantly found in red wine, significantly reversed lipopolysaccharide-induced decrease in SOD activity but only slightly (and not significantly) improved the lipopolysaccharide-induced decrease in GPx activity ${ }^{(50)}$. By contrast, in the ethanol-induced oxidative stress model, MitoVit E has been reported to mitigate ethanol-induced suppression of $\mathrm{GPx} /$ glutathione reductase functions, protein expression of $\gamma$-glutamylcysteine synthetase and total cellular glutathione levels ${ }^{(23)}$. Whether MitoVit E might also alter the levels of oxidised/reduced glutathione and $\boldsymbol{\gamma}$-glutamylcysteine synthetase in our model is still unknown and needs to be studied in the future.

In summary, the present study found that MitoVit $\mathrm{E}$ did not affect mitochondrial ATP or $\mathrm{H}_{2} \mathrm{O}_{2}$ (when succinate was the substrate) production rates in both the liver and the gastrocnemius. However, MitoVit E increased the number and average size of the subsarcolemmal, though not the intermyofibrillar, mitochondria in the soleus muscle of MF diet-fed mice. In addition, the combination of the LF diet and MitoVit $\mathrm{E}$ administration decreased the urinary isoprostane concentration most effectively. Finally, MitoVit E increased plasma SOD but not GPx activity in MF diet-fed mice.

\section{Acknowledgements}

The authors acknowledge Dr Harry Horner and Randy Denadel for helping in the transmission electron microscopy measurements, Yuhong Liu for valuable suggestions in the mitochondrial preparation and measurements of the mitochondrial ATP and $\mathrm{H}_{2} \mathrm{O}_{2}$ production rates, and Dr Lorene Leiter and Peter Scarbrough for the critical reading and correction of the manuscript. The present study was supported by the Nutrition and Wellness Research Center/USDA at Iowa State University. G. M. conducted the study, collected and analysed the data, and drafted the manuscript. G. A. K. and I. K. synthesised MitoVit E. M. E. S. and D. C. B. designed and supervised the study. T. B. B. provided the statistical assistance. All authors read and approved the final manuscript. The authors have no conflicts of interest.

\section{References}

1. Stock D, Gibbons C, Arechaga I, et al. (2000) The rotary mechanism of ATP synthase. Curr Opin Struct Biol 10, 672-679.

2. Fariss MW, Chan CB, Patel M, et al. (2005) Role of mitochondria in toxic oxidative stress. Mol Interv 5, 94-111.

3. Ischiropoulos H \& Beckman JS (2003) Oxidative stress and nitration in neurodegeneration: cause, effect, or association? J Clin Invest 111, 163-169. 
4. Trifunovic A \& Larsson NG (2008) Mitochondrial dysfunction as a cause of ageing. J Intern Med 263, 167-178.

5. Mates JM, Perez-Gomez C \& Nunez de Castro I (1999) Antioxidant enzymes and human diseases. Clin Biochem 32 , 595-603.

6. McCall MR \& Frei B (1999) Can antioxidant vitamins materially reduce oxidative damage in humans? Free Radic Biol Med 26, 1034-1053.

7. Valko M, Leibfritz D, Moncol J, et al. (2007) Free radicals and antioxidants in normal physiological functions and human disease. Int J Biochem Cell Biol 39, 44-84.

8. Henchcliffe C \& Beal MF (2008) Mitochondrial biology and oxidative stress in Parkinson disease pathogenesis. Nat Clin Pract Neurol 4, 600-609.

9. Forno LS (1996) Neuropathology of Parkinson's disease. J Neuropathol Exp Neurol 55, 259-272.

10. Squitieri F, Cannella M, Sgarbi G, et al. (2006) Severe ultrastructural mitochondrial changes in lymphoblasts homozygous for Huntington disease mutation. Mech Ageing Dev 127, 217-220.

11. Mattson MP \& Magnus T (2006) Ageing and neuronal vulnerability. Nat Rev Neurosci 7, 278-294.

12. Beal MF (2005) Mitochondria take center stage in aging and neurodegeneration. Ann Neurol 58, 495-505.

13. Evans JL, Goldfine ID, Maddux BA, et al. (2002) Oxidative stress and stress-activated signaling pathways: a unifying hypothesis of type 2 diabetes. Endocr Rev 23, 599-622.

14. Wlodek D \& Gonzales M (2003) Decreased energy levels can cause and sustain obesity. $J$ Theor Biol 225, 33-44.

15. Song BJ, Moon KH, Olsson NU, et al. (2008) Prevention of alcoholic fatty liver and mitochondrial dysfunction in the rat by long-chain polyunsaturated fatty acids. J Hepatol $\mathbf{4 9}$, $262-273$.

16. Stadtman ER (1988) Biochemical markers of aging. Exp Gerontol 23, 327-347.

17. Harman D (1991) The aging process: major risk factor for disease and death. Proc Natl Acad Sci U S A 88, 5360-5363.

18. Matthews RT, Yang L, Browne S, et al. (1998) Coenzyme Q10 administration increases brain mitochondrial concentrations and exerts neuroprotective effects. Proc Natl Acad Sci U S A 95, 8892-8897.

19. Miquel J, Ferrandiz ML, De Juan E, et al. (1995) $\mathrm{N}$-acetylcysteine protects against age-related decline of oxidative phosphorylation in liver mitochondria. Eur J Pharmacol 292 , 333-335.

20. Sokol RJ, McKim JM Jr, Goff MC, et al. (1998) Vitamin E reduces oxidant injury to mitochondria and the hepatotoxicity of taurochenodeoxycholic acid in the rat. Gastroenterology 114, 164-174.

21. Smith RA, Porteous CM, Gane AM, et al. (2003) Delivery of bioactive molecules to mitochondria in vivo. Proc Natl Acad Sci U S A 100, 5407-5412.

22. Murphy MP \& Smith RA (2007) Targeting antioxidants to mitochondria by conjugation to lipophilic cations. Annu Rev Pharmacol Toxicol 47, 629-656.

23. Siler-Marsiglio KI, Pan Q, Paiva M, et al. (2005) Mitochondrially targeted vitamin $\mathrm{E}$ and vitamin $\mathrm{E}$ mitigate ethanolmediated effects on cerebellar granule cell antioxidant defense systems. Brain Res 1052, 202-211.

24. Dhanasekaran A, Kotamraju S, Kalivendi SV, et al. (2004) Supplementation of endothelial cells with mitochondria-targeted antioxidants inhibit peroxide-induced mitochondrial iron uptake, oxidative damage, and apoptosis. $\mathrm{J} \mathrm{Biol} \mathrm{Chem}$ 279, 37575-37587.

25. Jauslin ML, Meier T, Smith RA, et al. (2003) Mitochondriatargeted antioxidants protect Friedreich Ataxia fibroblasts from endogenous oxidative stress more effectively than untargeted antioxidants. FASEB J 17, 1972-1974.

26. Ichikawa T \& Kato T (1968) Synthetic studies of alphatocopherol. I. Synthesis of alpha-tocopheryl acetate. Bull Chem Soc Jpn 41, 1224-1228.

27. Spivak AY, Knyshenko OV, Mallyabaeva MI, et al. (2006) Synthesis of alpha-tocopherol and naphthotocopherol analogs with a carboxyl group in the side chain. Russian Chem Bull 55, 306-311.

28. Grisar JM, Petty MA \& Bolkenius F (2003) Preparation of (Dibydrohydroxytetramethylbenzopyranyl)ethylphosphonium Bromide Derivs. as Cardioprotective Tocopherol Analogs. Canada: Merrell Dow Pharmaceuticals, Inc., USA

29. Cawthon D, McNew R, Beers KW, et al. (1999) Evidence of mitochondrial dysfunction in broilers with pulmonary hypertension syndrome (Ascites): effect of $t$-butyl hydroperoxide on hepatic mitochondrial function, glutathione, and related thiols. Poult Sci 78, 114-124.

30. Chappell JB \& Perry SV (1954) Biochemical and osmotic properties of skeletal muscle mitochondria. Nature 173, 1094-1095.

31. Mansouri A, Muller FL, Liu Y, et al. (2006) Alterations in mitochondrial function, hydrogen peroxide release and oxidative damage in mouse hind-limb skeletal muscle during aging. Mech Ageing Dev 127, 298-306.

32. Muller FL, Liu Y \& Van Remmen H (2004) Complex III releases superoxide to both sides of the inner mitochondrial membrane. J Biol Chem 279, 49064-49073.

33. Bradford MM (1976) A rapid and sensitive method for the quantitation of microgram quantities of protein utilizing the principle of protein-dye binding. Anal Biochem 72, $248-254$.

34. Morrow JD \& Roberts LJ 2nd (1996) The isoprostanes. Current knowledge and directions for future research. Biochem Pharmacol 51, 1-9.

35. Kadiiska MB, Gladen BC, Baird DD, et al. (2005) Biomarkers of oxidative stress study II: are oxidation products of lipids, proteins, and DNA markers of $\mathrm{CCl}_{4}$ poisoning? Free Radic Biol Med 38, 698-710.

36. Keaney JF Jr, Larson MG, Vasan RS, et al. (2003) Obesity and systemic oxidative stress: clinical correlates of oxidative stress in the Framingham study. Arterioscler Thromb Vasc Biol 23, 434-439.

37. Furukawa S, Fujita T, Shimabukuro M, et al. (2004) Increased oxidative stress in obesity and its impact on metabolic syndrome. J Clin Invest 114, 1752-1761.

38. Vincent HK, Powers SK, Stewart DJ, et al. (1999) Obesity is associated with increased myocardial oxidative stress. Int $J$ Obes Relat Metab Disord 23, 67-74.

39. Ozata M, Mergen M, Oktenli C, et al. (2002) Increased oxidative stress and hypozincemia in male obesity. Clin Biochem 35, 627-631.

40. Mao G, Kraus GA, Kim I, et al. (2010) A mitochondriatargeted vitamin $\mathrm{E}$ derivative decreases hepatic oxidative stress and inhibits fat deposition in mice. J Nutr $\mathbf{1 4 0}$, 1425-1431.

41. Smith RA, Porteous CM, Coulter CV, et al. (1999) Selective targeting of an antioxidant to mitochondria. Eur J Biochem 263, 709-716.

42. Bonnard C, Durand A, Peyrol S, et al. (2008) Mitochondrial dysfunction results from oxidative stress in the skeletal muscle of diet-induced insulin-resistant mice. J Clin Invest 118, 789-800.

43. Baloyannis SJ (2006) Mitochondrial alterations in Alzheimer's disease. J Alzheimers Dis 9, 119-126. 
44. Moreira PI, Carvalho C, Zhu X, et al. (2010) Mitochondrial dysfunction is a trigger of Alzheimer's disease pathophysiology. Biochim Biophys Acta 1802, 2-10.

45. Wu JH, Ward NC, Indrawan AP, et al. (2007) Effects of alphatocopherol and mixed tocopherol supplementation on markers of oxidative stress and inflammation in type 2 diabetes. Clin Chem 53, 511-519.

46. Devaraj S, Tang R, Adams-Huet B, et al. (2007) Effect of highdose alpha-tocopherol supplementation on biomarkers of oxidative stress and inflammation and carotid atherosclerosis in patients with coronary artery disease. Am J Clin Nutr 86, $1392-1398$

47. Hasty AH, Gruen ML, Terry ES, et al. (2007) Effects of vitamin $\mathrm{E}$ on oxidative stress and atherosclerosis in an obese hyperlipidemic mouse model. J Nutr Biochem 18, 127-133.
48. Stanek A, Cieslar G, Romuk E, et al. (2010) Decrease in antioxidant status of plasma and erythrocytes from patients with ankylosing spondylitis. Clin Biochem 43, 566-570.

49. Shen X, Tang Q, Wu J, et al. (2009) Effect of vitamin E supplementation on oxidative stress in a rat model of dietinduced obesity. Int J Vitam Nutr Res 79, 255-263.

50. Sebai H, Sani M, Yacoubi MT, et al. (2010) Resveratrol, a red wine polyphenol, attenuates lipopolysaccharide-induced oxidative stress in rat liver. Ecotoxicol Environ Saf $\mathbf{7 3}$, 1078-1083.

51. Fernandez-Pachon MS, Berna G, Otaolaurruchi E, et al. (2009) Changes in antioxidant endogenous enzymes (activity and gene expression levels) after repeated red wine intake. J Agric Food Chem 57, 6578-6583. 